\title{
HIV infection: social network, social support, and CD4 lymphocyte values in infected homosexual men in Malmö, Sweden
}

\author{
Leif Persson, Bo Gullberg, Bertil S Hanson, Torkil Moestrup, Per-Olof Östergren
}

\begin{abstract}
Study objective - The aim was to determine if there is an association between social network and social support and the CD4 cell count in HIV infected homosexual men.

Design - The study was cross sectional. A structured questionnaire assessing psychosocial factors such as social network and social support was administered at interview. Information on CD4 cell counts and HIV symptoms were obtained from participants' medical records.

Setting - The study population consisted of all HIV seropositive homosexual and bisexual men who had not been diagnosed as having AIDS seen at the Department of Infectious Diseases, the only hospital clinic in the city of Malmö (230000 inhabitants), Sweden that provides care for HIV infected patients.

Participants - Altogether 47 (68\%) of 69 men in the population agreed to be interviewed.

Main results - A low CD4 cell count was found more frequently in men with low social participation scores (OR $3 \cdot 3 ; 95 \%$ CI $1 \cdot 0,11)$, in those with a low adequacy of social participation (OR 3.8; 95\% CI 1.1, $13)$, and in men with low material support scores (OR 3.9; 95\% CI 1·1, 13). After adjustment for age and time of awareness of the HIV infection, the two former associations remained statistically significant.

Conclusions - These results, if reproduced in a longitudinal study, might suggest that psychosocial factors can affect an individual's immune system.
\end{abstract}

\section{(f Epidemiol Community Health 1994;48:580-585)}

Department of Community Health Sciences

L Persson

B Gullberg

B S Hanse

P-O Östergren

and Department of Infectious Diseases T Moestrup

Lund University, Malmö General Hospital, S-21401 Malmö, Sweden

Correspondence to: Mr L Persson

Accepted for publication March 1994
Patients with good social support also seem to have a longer survival time after the diagnosis of AIDS than those with poor social support. ${ }^{4}$ In another Chicago study ${ }^{5}$ of homosexual men, increasing involvement in the gay community extended the survival time, while depression had the opposite effect.

Prospective studies show that psychosocial factors, such as social network and social support, influence both morbidity and mortality of a wide range of diseases. ${ }^{6-9}$ Several different mechanisms and pathways have been suggested to explain the association. For example, the effects on health could be mediated through differing lifestyles or risk factors in different social environments. ${ }^{10}$ Social network and social support could also maintain health more directly, as suggested by the theory of host susceptibility presented by Cassel in $1976 .^{11}$ This theory focusses on factors in the psychosocial environment that, by acting as stressors or as buffers for stress, could influence the susceptibility of the individual by affecting the major physiological regulating mechanisms of the body, for example neuroendocrine or immunological processes or both. ${ }^{12-20}$

Particular pathways between psychosocial factors and the development of symptoms of HIV have been discussed by Blaney et al. ${ }^{21}$ The results of their study show that good social support (both functional and structural aspects) is associated with less distress in a group of HIV seropositive gay men. Support for an association between psychosocial factors and specific immune functions have been reported by several researchers. Evans has shown a stress related reduction in natural killer cells, ${ }^{22}$ and Goodwin has shown that bereavement is associated with changes in cellular immune function in HIV-1 seropositive gay men. ${ }^{23}$

The largest group of HIV infected persons in the United States, northern Europe, and other industrialised parts of the world is men who have sex with other men. ${ }^{24}$ Most studies of homosexual men, however, are based on selected populations such as men enrolled at clinics for sexually transmitted diseases where it was not possible to define clearly the catchment area, at gay meeting places, or through advertisements in papers and magazines. ${ }^{25}$ These ways of generating a study population introduce a risk that the individuals will not be representative of the total population of HIV seropositive gay men, which constitutes a problem when generalising results from these studies.

We aimed to investigate if there is an association between different aspects of social 
network and social support and CD4 cell counts in a representative city population of HIV seropositive gay men.

\section{Methods}

STUDY POPULATION

This cross sectional study is part of a prospective study of the influence of different psychosocial factors on the progression of HIV infection. The study population consisted of all detected HIV seropositive homosexual and bisexual men residing in Malmö, who had not received an AIDS diagnosis applying the CDC classification, ${ }^{26}$ and who where in contact with the Department of Infectious Diseases at Malmö General Hospital, during the one year April 1988 to May 1989.

This clinic is the only one in the city of Malmö (230 000 inhabitants), Sweden, that provides care for HIV infected patients. Almost all patients who are detected in other clinics are referred to this department. Therefore, almost all known HIV seropositive homosexual and bisexual men in Malmö, are known to this department.

The total number of known HIV seropositive people in Malmö in December 1988 was 136, of whom 103 were homosexual and bisexual men. Of all gay men who had required care or died of AIDS in Malmö up to December 1988 $(n=22), 15(68 \%)$ were already known as seropositive in the Department of Infectious Diseases. This suggests that most HIV seropositive homosexual and bisexual men in Malmö are known, and that the 103 men probably comprised the majority of all HIV seropositive homosexual and bisexual men in Malmö.

Twenty two men had received an AIDS diagnosis before the time of the study. Twelve men had been tested anonymously and were not in contact with the department during the year when the population was defined. One of the gay men was provided with care by a physician outside the Department of Infectious Diseases. Thus, the study population comprised 68 men. Of these men, $47(68 \%)$ responded to the invitation to take part in the study. In order to investigate whether the participants were representative of all the men eligible for the study, backgrund variables were compared for both participants and non-participants. ${ }^{27}$ No statistically significant differences were found.

\section{STUDY METHODS}

All men were interviewed consecutively by one member of the team, which consisted of two counsellors and one physician. A structured questionnaire was used. In order to standardise the interviews, the team discussed the questionnaire in advance and also undertook pilot interviews. The questionnaire contained items assessing psychosocial factors, such as aspects of social network and social support, and also sexual orientation, and sexual contact patterns (see appendix). The social network and social support scales were developed at the Department of Community Health Sciences in Malmö. They have been used and validated in various population studies, and have shown an acceptable internal consistency and high reliability. ${ }^{89} 2829$

Antibodies to HIV were assessed by enzyme linked immunosorbent assay (ELISA), ${ }^{30}$ confirmed by Western blotting. ${ }^{31}$ Seropositive HIV antibody status was considered to be confirmed when both tests were positive.

Symptoms of HIV infection, according to the CDC classification, ${ }^{26}$ were recorded in a standardised way at a clinical examination performed by a physician, on one or several occasions during the one year period. In the analysis, subjects were classified into one group with no or only mild symptoms (CDC classification II-III) and another with severe symptoms (CDC classification IV). ${ }^{26}$ We considered it improper to attempt a more detailed scaling of the symptoms, since the CDC classification IV contains very disparate types of symptoms, and does not allow a useful severity ranking.

At the clinical examination the $\mathrm{CD} 4$ cell count (CD4 lymphocytes/ $\mu \mathrm{l}$ ) was assessed in a standardised way. ${ }^{32}$ In the analysis the mean CD4 lymphocyte count was computed from the distribution of all CD4 values for each individual during the study period (the median number of values $=3$, range 1-7), and was dichotomised at the median $(416 / \mu \mathrm{l})$.

Subjects were grouped according to social class, based on the individual's profession, working tasks and position. Social class III was defined as skilled and unskilled workers, social class II included middle range civil servants and employees. Social class I comprised persons in leading positions, professionals with university degrees, and owners of business enterprises with employees. ${ }^{33}$

Immigrants were defined as those men who were born outside Sweden.

The study has been approved by the ethics committee of Lund University.

SOCIAL NETWORK AND SOCIAL SUPPORT

An individual's social newtork (social ties in a 'structural' sense) and social support (a 'function' of the individual's interaction with his social network) are considered important psychosocial resources in the process of coping with demands and stressful situations in daily life. ${ }^{891128}$

Social network

Five subconcepts of social network were defined as follows:

(1) General index of social network constitutes an overall index of social network, tapping the major domains of the network (friends and acquaintances, family, social organisations, and occupational environment).

(2) Family contact frequency is a quantitative measure based on the frequency of personal interaction with the family.

(3) Social anchorage describes the quality of the relationship between the individual and his social network and his identification with different domains of the network. It differs from the measures of social support in that it 
Table 1 Association between background factors and CD4 counts for the 47 men

\begin{tabular}{|c|c|c|c|}
\hline Background factors & $\begin{array}{l}\text { CD4 } \\
\text { low } \\
(n=23)\end{array}$ & $\begin{array}{l}C D 4 \\
\text { high } \\
(n=24)\end{array}$ & $O R(95 \% C I)$ \\
\hline \multicolumn{4}{|l|}{ Age (y): } \\
\hline $\begin{array}{l}<37 \\
>37\end{array}$ & 14 & 9 & \\
\hline \multirow{2}{*}{\multicolumn{4}{|c|}{$\begin{array}{l}\text { Social class: } \\
\text { Social class III }\end{array}$}} \\
\hline Social class III & 13 & & \\
\hline Social class II & 10 & 13 & $1.5(0.5,4.9)$ \\
\hline \multicolumn{4}{|l|}{$\begin{array}{l}\text { Immigrant status: } \\
\text { Immigrant }\end{array}$} \\
\hline \multicolumn{4}{|l|}{$\begin{array}{l}\text { Interval since first visit to the } \\
\text { clinic: }\end{array}$} \\
\hline $\begin{array}{l}\text { Cinic: } \\
\text { Long }\end{array}$ & 15 & 8 & \\
\hline Short & 8 & 16 & $3 \cdot 8(1 \cdot 1,13)$ \\
\hline \multicolumn{4}{|l|}{ Having severe HIV symptoms: } \\
\hline Yes & 12 & 6 & \\
\hline No & 11 & 18 & $3 \cdot 3(1 \cdot 0,11)$ \\
\hline
\end{tabular}

Table 2 Univariate and adjusted odds ratios (OR) and 95\% confidence interval (95\% CI) regarding the association between social network and social support and the CD4 lymphocytes count in 47 gay men

\begin{tabular}{|c|c|c|c|c|}
\hline $\begin{array}{l}\text { Social network } \\
\text { indices } \\
\text { (CD4 median for each } \\
\text { group }(\mid \mu l))\end{array}$ & $\begin{array}{l}C D 4 \\
\text { low } \\
(n=23)\end{array}$ & $\begin{array}{l}C D 4 \\
\text { high } \\
(n=24)\end{array}$ & $\begin{array}{l}\text { Univariate } \\
\text { OR }(95 \% C I)\end{array}$ & $\begin{array}{l}\text { Adjusted* } \\
\text { OR }(95 \% \text { CI })\end{array}$ \\
\hline \multicolumn{5}{|l|}{ Social network: } \\
\hline Low (393) & 13 & 13 & & \\
\hline High (433) & 10 & 11 & $1 \cdot 1(0 \cdot 4,3 \cdot 5)$ & $1 \cdot 5(0 \cdot 4,5 \cdot 5)$ \\
\hline \multicolumn{5}{|l|}{ Family contact frequency: } \\
\hline High (433) & 15 & 16 & $1 \cdot 1(0 \cdot 3,3 \cdot 6)$ & $1.5(0.4,5 \cdot 5)$ \\
\hline \multicolumn{5}{|l|}{ Social participation: } \\
\hline Low (315) & 12 & 6 & & \\
\hline High (448) & 11 & 18 & $3 \cdot 3(1 \cdot 0,11)$ & $8 \cdot 1(1 \cdot 6,40)$ \\
\hline \multicolumn{5}{|l|}{ Adequacy of social participation: } \\
\hline Low (341) & 15 & 8 & & \\
\hline High (456) & 8 & 16 & $3 \cdot 8(1 \cdot 1,13)$ & $5 \cdot 8(1 \cdot 4,24)$ \\
\hline \multicolumn{5}{|l|}{ Social anchorage: } \\
\hline High (408) & 15 & 15 & $0.9(0.3,2.9)$ & $2 \cdot 1(0 \cdot 5,8 \cdot 7)$ \\
\hline \multicolumn{5}{|l|}{ Emotional support: } \\
\hline Low (341) & 11 & 6 & & \\
\hline High (445) & 12 & 18 & $2 \cdot 8(0 \cdot 8,9)$ & $3 \cdot 4(0 \cdot 8,13)$ \\
\hline \multicolumn{5}{|l|}{ Material support: } \\
\hline High (468) & 10 & 18 & $3.9(1 \cdot 1,13)$ & $3.3(0.9,13)$ \\
\hline \multicolumn{5}{|l|}{ Partner support: } \\
\hline No $(440)$ & 8 & 10 & & \\
\hline Yes $(400)$ & 15 & 14 & $0.8(0.2,2.4)$ & $1 \cdot 2(0 \cdot 3,4 \cdot 4)$ \\
\hline
\end{tabular}

*Adjusted for age and time since the first visit to the clinic.

applies to the structural level and not to the individual network links. Low social anchorage could be thought of as a form of alienation.

(4) Social participation represents the individual's social activity in a variety of social arenas.

(5) Adequacy of social participation reflects whether a person is satisfied with his possibilities of participating in social activities.

\section{Social support}

Three subconcepts of social support were defined as follows:

(1) Emotional support was defined as the social network's ability to satisfy the individual's needs of sharing emotions and problems and of receiving confidential advice and encouragement through specified personal links with other network members.

(2) Material support reflects access to practical services and material resources through specified network links.

(3) 'Partner' support was defined according to the presence or not of a partner (that is, a lover or a 'spouse', with whom the men were cohabiting or not).

The wording of the items included in the social network and social support indices are

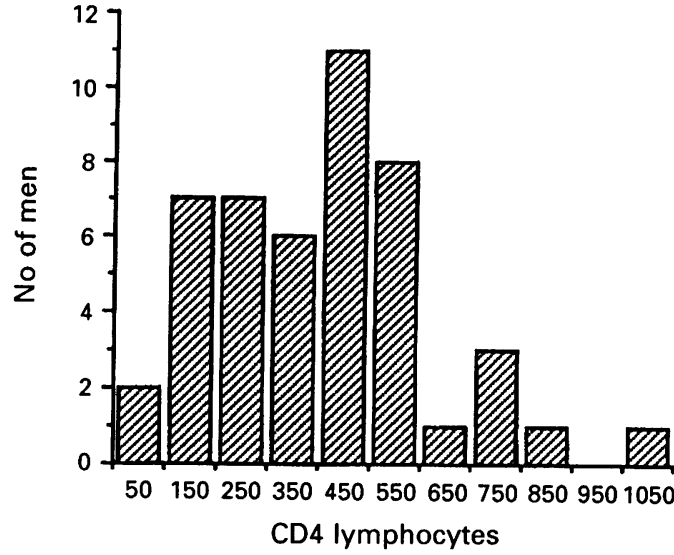

Distribution of CD4 cell counts (CD4 lymphocytes / $\mu l$, interval midpoints) in the 47 HIV positive men in the study group

presented in the appendix. ${ }^{34}$ The distributions of each item have been dichotomised as closely to the median as possible. Men with scores above the median were given one point and the others zero. The points of the items of each index were then summarised for each individual to form the score on the index in question. Values under the median of each index were defined as low social network and low social support, respectively.

\section{STATISTICAL METHODS}

Odds ratio (OR) and $95 \%$ confidence intervals (CI) were calculated to provide quantitative estimates of the associations between the background variables and aspects of social network and social support on the one hand, and the CD4 lymphocyte values on the other. ORs were adjusted for age and time since the first visit to the clinic (as a continuous variable) in a logistic regression analysis.

\section{Results}

The median age of the 47 participants was 37 years (range 23-53 years). Twenty four (51\%) of the men belonged to social class III, and 23 to social class II, and none to social class I. Of the 12 immigrants, five came from Scandinavia, three from other European countries, and four from North or South America. The median interval since the first visit was 44 months (range 5-58 months). The mean (SD) CD4 lymphocyte count was $403(207) / \mu l$, and the median was 416 (range 64-1015) / $\mu$ l (figure). Eighteen men (38\%) had HIV related symptoms.

Table 1 shows that a higher proportion of men with a low CD4 count (below the median) were below 37 years of age (OR $2 \cdot 6$; $95 \%$ CI $0 \cdot 8,8 \cdot 4)$. Stastistically significant associations were found between a low CD4 count and having HIV symptoms, and having a longer than median time $(3 \cdot 1$ years $)$ since the first visit to the clinic (OR 3.3; 95\% CI 1.0, 11) and (OR $3 \cdot 8 ; 95 \%$ CI $1 \cdot 1,13$ ) respectively (table 1).

A low score on three of the eight social network and social support indices showed 
statistically significant associations with a low CD4 count (table 2). A higher proportion of men with a low CD4 count was found in those with low social participation (OR 3.3; 95\% CI $1 \cdot 0,11)$, low adequacy of social participation (OR $3.8 ; 95 \%$ CI $1 \cdot 1,13$ ) and in those with low material support (OR 3.9; $95 \%$ CI $1 \cdot 1$, 13). For men who had a low score on the emotional support index, the results indicated a more than doubled risk of having a low CD4 count. This result, however, was not statistically significant (OR $2 \cdot 8 ; 95 \%$ CI $0 \cdot 8,9$ ) (table 2 ).

Men with a low CD4 count were more often young and had been aware of their infection for a longer time. A logistic regression analysis was therefore performed to adjust for the possible confounding influence of these two factors (table 2). After the adjustment, the associations between the CD4 count and social participation and adequacy of social participation, remained statistically significant, even with increasing odds radios (OR $8 \cdot 1 ; 95 \%$ CI $1 \cdot 5,39$ and OR 5.8; 95\% CI 1.3, 22, respectively). The material support index, however, failed to reach a statistically significant level after the adjustment, although the odds ratio were still high (OR 3.3; CI 0.9, 13) (table 2).

\section{Discussion}

This study aimed to investigate whether there is an association between social network and social support factors and the total $\mathrm{CD} 4$ count of the individual, an aspect of immunocompetence. A low score on two social network indices (social participation and adequacy of social participation) was statistically significantly associated with a low CD4 lymphocyte count, independently of age and time since first visit to the clinic.

The population invited to participate in this study consisted of all but one of the detected and identified seropositive gay men without an AIDS diagnosis in the city of Malmö, Sweden. A few men may have been tested outside Malmö, but most gay men who have been diagnosed in Malmö during recent years have been known as seropositive patients at the Department of Infectious diseases in Malmö General Hospital. Thus, the study population can be regarded as being fairly representative of all HIV infected gay men in Malmö. This can be explained in part by the facts that only one hospital department cares for HIV infected patients in Malmö and that many homosexual men in Sweden know of their HIV antibody status. This latter point may be due to the Swedish policy of HIV antibody testing, which is somewhat different to that in other countries. Here, an individual's awareness of his or her HIV antibody status is seen as an important part in preventing the transmission of the infection. For people who believe they may have been exposed to HIV infection, testing is strongly encouraged. It is also easy to get access to a test which is free of charge.

In several other studies the non-participants have differed from the participants in that they have had less education, been more socially isolated, and had a higher morbidity and mortality. ${ }^{3536}$ In this study, however, a comparison of background variables between participants and non-participants showed only slight, and no statistically significant, differences. ${ }^{27}$

A major problem is the rather low level of statistical power of the analyses. This situation could not, however, be altered because of the small number of individuals relevant for this study. The consistent associations between a low CD4 count and exposure to a low score on several of the social network and social support measures indicates that even though many of them do not reach statistical significance, several more components of social network and social support might be of interest in relation to immune competence and well worth testing in a more powerful study design.

In the process of deciding when and whether or not to take the HIV test, bias could be introduced in a cross sectional study. A good social network and social support might increase the tendency of early testing and detection. If this is the case, the most socially connected men will represent a group who are earlier in the course of the infection and will, as a result, have higher CD4 counts. These problems can, however, only be overcome in a prospective study design in which the social network and support of the individual is assessed at baseline and the test behaviour is studied during the follow up period.

In our sample, we found a significant correlation $(r=0.5)$ between the infection date and the date of first contact with the clinic in 13 cases where the infection date was known. These 13 men did not differ significantly from the men with an unknown date of infection with regard to age $(34.9(5 \cdot 7)$ years versus $36 \cdot 1$ (8.7) years), social class $(40 \%$ white collar versus $55 \%)$, cohabiting ( $60 \%$ versus $64 \%)$ and CD4 count (407 (251) versus $394(205) / \mu \mathrm{l})$. Because of this we used the time since the first contact date as a proxy for time since infection in a multivariate analysis of confounding of the association with social network and social support. This changed the univariate findings very marginally which suggests that this type of confounding could not explain our findings. However, the interval between the date of infection and testing - that is, the first CD4 measurement - was most certainly misclassified, in a non-differential way. Thus, a larger true confounding effect cannot be totally ruled out. ${ }^{37}$

Besides age and lapse of time, Solomon et al have suggested five potentially confounding variables of importance when studying the associations between psychosocial variables and immunity in the context of HIV infection ${ }^{18}$ as follows:

Medication may affect the immune system. Before the period of the study, all men, regardless of CD4 count, were invited to join a double blind, placebo-controlled drug trial for six months with Isoprinosine. Twenty four of the 47 men in our study took the drug, and some of the men continued to take the drug during the study period. However, the result 
of this drug trial was that no effect was seen on the level of CD4 lymphocytes, and that there was no difference in the progression of the men's conditions between the Isoprinosine group and the placebo group. ${ }^{38}$ Three men also used AZT. These three men, however, who thus were on medication that could have a positive impact on the CD4 status, all had a CD4 count under the median level for the study population $(<416 / \mu \mathrm{l})$. Thus, the medication variable for these three men could not have affected the classification of the CD4 status in this study.

Severity of symptoms may influence the psychosocial functioning. We found an association between a low CD4 count and severe HIV symptoms and HIV symptoms could therefore be a potential confounder on the same grounds as awareness of a low CD4 count. This could not be handled easily in the analysis, however, since it is also a sign of progression of the HIV infection. Bearing this in mind, we nevertheless included the HIV symptom severity variable in regression analysis together with age and each of the social network and social support factors. This changed the univariate findings only marginally, however, and did not affect the statistical significance in either direction.

Viral cofactors, such as Epstein-Barr virus (EBV) and cytomegalovirus (CMV), can accompany and/or exacerbate HIV and its immunological consequences and may themselves be psychosocially influenced. As for the mere presence of CMV and EBV antibodies, almost all sexually active homosexual men show positive tests, so this is not likely to be a confounding factor in this study. ${ }^{39}$ The influence of an active CMV or EBV infection on the progress of the HIV infection is imperfectly understood, however, and could thus have a confounding effect. ${ }^{40}$ It has not been possible to consider the importance of these viral cofactors in this study since no data were available.

Behaviours such as drug and alcohol use, exercise, smoking, and nutrition may have an impact on the immune system. These different lifestyle factors should not, in our view, be considered as confounding variables, but as part of a different possible causal pathway between the psychosocial factors and the immune system. ${ }^{29}$

Central nervous system involvement of HIV may be of importance both in terms of alteration of emotional responses and by a possible impairment of neuroimmunoregulation. Central nervous system involvement was not systematically measured in this study but all the men were well assessed clinically and did not show any apparent central nervous system disturbances during the study period.

Since this is a cross sectional study it is not possible to determine the direction of causation between the assessed variables. If the results of this study are confirmed in a larger prospective study they would suggest that an environment that offers opportunities for social participation and social involvement is of importance as a protective factor against deteoriation of immune competence in HIV positive individuals.

\section{Appendix}

I SOCIAL NETWORK

(1) How many close friends do you have, ie persons who you think you know very well and with whom you can talk about almost anything (do not count relatives)? (actual number)*

(2) How many relatives do you feel close to? (actual number)*

(3) Are you a member of any religious or political associations or trade union, and regularly attend meetings and other activities? (2)*

(4) How many friends and acquaintances do you have, ie persons that you may not know very well but whom you socialise with once or more during a year? (actual number)*

(5) Do you work/study together with any other persons or alone? (3)* (5 items)

\section{FAMILY CONTACT FREQUENCY}

(1) How often do you personally interact with: (children, mother, father, siblings) $(9)^{*}(4$ items)

\section{SOCIAL ANCHORAGE}

(1) Would you say that you are rooted and feel a strong affinity to your:

Residential area? (4)*

Work mates/schoolmates and place of work school? (4)*

Formal groups (union, clubs, church etc)? (5)*

Family (broad sense)? (4)* (4 item's)

\section{SOCIAL PARTICIPATION}

(1) Which of the following activities have you taken part in during the last 12 months?

Work-related course/study circle (2)*

Non-work related course/study circle $(2)^{*}$

Union meeting (2)*

Other meeting of a formal group (2)*

Been to a theatre/cinema (2)*

Been to an art exhibition (2)*

Been to church (2)*

Been to a public sports event (2)*

Written a letter to the editor of a newspaper/ magazine (2)*

Taken part in a political or union rally $(2)^{*}$

Been to a place of public entertainment (dance, night club etc.) $(2)^{*}$

Taken part in a family gathering (2)*

Been to a private party $(2)^{*}(13$ items)

V ADEQUACY OF SOCIAL PARTICIPATION

(1) Are you satisfied with your opportunities as they are for the moment to participate in the above mentioned activities? (4)* $(1$ item)

\section{EMOTIONAL SUPPORT}

(1) If you were to have problems at work, ie in relations with work mates or a boss would you then have any person that you could talk to freely to get support and advice? (4)*

(2) If you were to have problems with family or close friends would you then have any person that you could talk to freely to get support and advice? (4)* 
(3) If you were to have HIV related health problems do you then have any person that you could talk to freely to get support and advice? (4)*

(4) If you were to get other health problems than HIV related ones would you then have any person that you could talk to freely to get support and advice? (4)*

(5) Do you have any person who totally accepts you as you are, with all your merits and shortages? $(4) *$ (5 items)

\section{MATERIAL SUPPORT}

(1) If you needed to borrow some small thing, eg a tool or household appliance, do you know of any person outside your own household that you could turn to? $(4)^{*}$

(2) If you needed to borrow some money, eg 500 SEK $(£ 50)$ for just a day or a weekend, do you know of anyone you could turn to? $(4)^{*}$ (3) If you were to fall ill and need to run some errands, do you know anyone outside your own household whom you could ask? (4)*

(4) If you needed help with some small repair work to be done in your home, do you know anybody outside your own household that could help you? $(4)^{*}(4$ items)

${ }^{*}$ Numbers of possible values of the variable.

This study has been supported by grants from the Swedish Medical Research Council and Medical Faculty of Lund University.

1 Solomon GF. Psychoneuroimmunology and human immunodeficiency virus infection. Psychiatric Med 1989;7: 47-57.

2 Kessler R, Joseph J, Ostrow D. Psychosocial co-factors in illness onset among HIV positive men. Proceedings of the $V$ international conference on AIDS. Montreal, Canada, 1989

3 Solano L, Costa M, Salvati S, Coda R, Aiuti F, Mezzaroma I, Bertini M. Psychosocial factors and symptomatic de, Bertini $M$. Psychosocial factors and symptomatic de-
velopment in HIV positive ss Proceedings of the VII Invelopment in HIV positive ss Proceedings of the VII

4 Reillo M. Psychosocial factors associated with prognosis in Aids. Proceedings of the VI International conference on AIDS. San Francisco, California, 1990.

5 Caumartin S, Joseph JG, Chmiel J. Premorbid psychosocial factors associated with differential survival time in AIDS patients. Proceedings of the VII International conference on AIDS. Florence, Italy, 1991.

6 Berkman LF, Syme L. Social networks, host resistance, and mortality: A nine-year follow-up study of Alameda County residents. Am F Epidemiol 1979; 109:186-204.

7 House JS, Robbins C, Metzner HL. The association of social relationships and activities with mortality: prospective evidence from the Tecumseh community study. Am J Epidemiol 1982;116:123-40.

8 Hanson BS. Social network, social support and health in elderly men. A population study. Malmö: Lund University, 1988. men. A pop
MD thesis.

9 Östergren P-O. Psychosocial resources and health. With special reference to social network, social support, and cardiovascular reference to social network, social support, and cardiovascu
disease. Malmö: Lund University, 1991. MD thesis.

10 Hanson BS, Isacsson S-O, Janzon L, Lindell S-E. Social network and social support influence mortality in elderly men. Am 7 Epidemiol 1989;130:100-111.

11 Cassel J. The contribution of the social environment to host resistance. Am $\mathcal{F}$ Epidemiol 1976;104:107-123.

12 Siegrist J, Siegrist K, Weber I. Sociological concepts in the etiology of chronic disease: the case of ischemic hear diseas. Soc Si Med 1986;22:247-53.

13 Maes S, Vingerhoets A, van Heck G. The study of stress and disease: some developments and requirements. Soc Sci Med 1987;25:567-78.

14 Ursin H. The physiology and pathophysiology of stress: How social support and networks affect somatic health In: Isacsson S-O, Janzon L, eds. Social support - health and disease (Sixth International Berzelius symposium). Malmö Almqvist \& Wiksell International, 1986: 37-48.

15 Henry JP, Stephens PM. Stress, health, and the social en- vironment. A sociobiologic approach to medicine. New York: Springer Verlag, 1977.

16 Thomas PD, Goodwin JM, Goodwin JS Effect of social support on stress-related changes in cholesterol level, uric acid level and immune function in an elderly sample. $A m$ f Psychiatry 1985;142:735-7.

17 Bartrop RW, Lazarus L, Luckhurst E, Kiloh LG, Penny R. Depressed lymphocyte function after bereavement. Lancet 1977;1:834-6

18 Solomon GF, Kemeny ME, Temoshok L. Psychoneuroimmunologic aspects of human immunodeficiency virus infection. In: Ader R, Felten DL, Cohen N, eds. Psychoneuroimmunology. San Diego, California: Academic Press, 1991: 1081-113.

19 Ader R, Felten DL, Cohen N, eds. Psychoneuroimmunology. 2nd ed. San Diego, California: Academic Press, 1991.

20 Cohen S, Tyrell DAJ, Smith AP. Psychological stress and susceptibility to the common cold. N Engl f Med 1991; 325:606-12.

21 Blaney NT, Goodkin K, Morgan RO, Feaster D, Millon C, Szapocznik J, Eisdorfer C. A stress-moderator model of distress in early HIV-1 infection: concurrent analysis of distress in early HIV-1 infection: concurrent analysis of
life events, hardiness and social support. $\mathcal{F}$ Psychosom Res life events, hardin

22 Evans D, Leserman J, Perkins DO, Stern RA, Van der Horst $\mathrm{CM}$, Hall CD, Folds JD. Stress related reduction of natural killer cells in HIV. Proceedings of VII International conference on AIDS. Florence, Italy, 1991.

23 Goodwin K, Blaney N, Fester D, Fletcher MA, Baum M, Szapocznik J, Eisdorfer C. Bereavement is associated with changes in cellular immune function in asymptomatic HIV-1 seropositive gay men. Proceedings of VII International conference on AIDS. Florence, Italy, 1991.

24 WHO. Reports from the World Health Organisation 1989 Geneva: WHO

25 McKusick L, Coates TJ. Morin SF, Pollack L, Hoff C. Longitudinal predictors of reductions in unprotected anal intercourse among gay men in San Francisco: The AIDS Behavioural Research Project. Am f Public Health 1990; 80:978-83.

26 Centers for Disease Control. Classification system for human T-lymphotropic virus type III/lymphadenopathyhuman T-lymphotropic virus type III/ymphadenopa

27 Persson L, Hanson BS, Östergren P-O, Moestrup T, Isacsson S-O. Awareness of HIV seropositivity and psyIsacsson S-O. Awareness of HIV seropositivity and psychosocial factors influence on the sexual contact pattern. A population study of HIV infected homosexual men, in
the City of Malmö, Sweden. fournal of Psychology and the City of Malmö, Sweden. Four

28 Hanson BS, Östergren P-O. Differential social network and social support characteristics, nervous problems and insomnia: Theoretical and methodological aspects on some results from the population study "Mer, born in 1914", Malmö, Sweden. Soc Sci Med 1987;25:849-59.

29 Hanson BS, Isacsson S-O, Janzon L, Lindell S-E. Social support and quitting smoking for good. Is there an association? - Results from the population study "Men born in 1914", Malmö, Swe the Addict Behav 1990;15:221-33.

30 in 1914", Malmo, Sweden. Addict Behav 1990;15:221-33. epidemiology of human T-lymphotropic virus type III among homosexual men with acquired immune deficiency among homosexual men with acquired immune deficiency syndrome or generalized lymphadenopathy and among asymptomatic

31 Groopman JE, Chen FW, Hope JA, et al. Serological characterization of HTLV-III infection in AIDS and related disorders. F Infect Dis 1986;153:736-41.

32 Reinherz EL, Schlossman SF. The differentiation and function of human T lymphocytes. Cell 1980;19:821-7.

33 Carlsson G. Social mobility and class structure. Lund: Gleerups, 1958.

34 Östergren P-O, Hanson BS, Isacsson S-O, Tejler L. Social network, social support and acute chest complaints among young and middle-aged patients in an emergency department. A case-control study. Soc Sci Med 1991;33: 257-67.

35 Janzon L, Hanson BS, Isacsson S-O, Lindell S-E, Steen B. Factors influencing participation in health surveys. Results from the prospective population study "Men born in 1914", in Malmö, Sweden. F Epidemiol Community Health 1986;40:174-7.

36 Bergstrand R, Vedin A, Wilhelmsson C, Wilhelmsson L. Bias due to non-participation and heterogenous sub-groups in due to non-participation and heterogenous sub-gro
population surveys. $\mathcal{C}$ Chron Dis 1983;36:725-8.

37 Phillips AN, Davey Smith G. How independent are "independent" effects? Relative risk estimation when correlated exposures are measured imprecisely. $\mathcal{f}$ Clin Epidemiol 1991:44:1223-31.

38 Pedersen C, Sandström E, Petersen CS, et al. The efficacy of inosine pranobex in preventing the acquired immunodeficiency syndrome in patients with human immunodeficiency virus infection. The Scandinavian Isoprinosine Study Group. (published erratum appears in $N$ Engl f Med 1990 Nov 8;323(19):1360). N Eng f Med 1990;322:1757-63.

39 Schattner A, Hanuka N, Sarov B, Sarov I, Handzel Z, Bentwich Z. Sequential serological studies of homosexual men with and without HIV-infection. Epstein-Barr virus activation preceding and following HIV seroconversion. Clin Exp Immunol 1991;85:209-13. 